ARTICLE

https://doi.org/10.1038/s41467-019-14254-3

\title{
Synthesis of difluoromethylated allenes through trifunctionalization of 1,3-enynes
}

Munira Taj Muhammad ${ }^{1,4}$, Yihang Jiao ${ }^{1,2,4}$, Changqing Ye $\mathrm{e}^{1,2,4}$, Mong-Feng Chiou (1) 1, Muhammad Israr ${ }^{1,2}$, Xiaotao Zhu', Yajun Li (1) ${ }^{1}$, Zhenhai Wen ${ }^{1,2}$, Armido Studer (10 ${ }^{3}$ \& Hongli Bao (1) ${ }^{1,2 \star ~}$

Organofluorine compounds have shown their great value in many aspects. Moreover, allenes are also a class of important compounds. Fluorinated or fluoroalkylated allenes might provide an option as candidates for drug and material developments, as allenes allow a great number of valuable transformations. Herein, we report a metal-free synthesis of difluoromethylated allenes via regioselective trifunctionalization of 1,3-enynes. This method proceeds through double $\mathrm{C}-\mathrm{F}$ bond formation with concomitant introduction of an amino group to the allene. Synthetic applications are conducted and preliminary mechanistic studies suggest that a twostep pathway is involved. DFT calculations revealed an unusual dibenzenesulfonimideassisted fluorination/fluoroamination with NFSI. In addition, kinetic reaction study revealed the induction period of both major and side products to support the proposed reaction mechanism. This work offers a convenient approach for the synthesis of a range of difluoromethylated allenes and is also a rare example of trifunctionalization of 1,3-enynes.

\footnotetext{
${ }^{1}$ State Key Laboratory of Structural Chemistry, Key Laboratory of Coal to Ethylene Glycol and Its Related Technology, Center for Excellence in Molecular Synthesis, Fujian Institute of Research on the Structure of Matter, University of Chinese Academy of Sciences, 155 Yangqiao Road West, Fuzhou, Fujian 350002, People's Republic of China. ${ }^{2}$ University of Chinese Academy of Sciences, Beijing 100049, People's Republic of China. ${ }^{3}$ Organisch-Chemisches Institut, Westfälische Wilhelms-Universität Corrensstraße 40, 48149 Münster, Germany. ${ }^{4}$ These authors contributed equally: Munira Taj Muhammad, Yihang Jiao, Changqing Ye. *email: hlbao@fjirsm.ac.cn
} 
O rganofluorine compounds have shown great importance over the years in the fields such as medicinal chemistry and agrochemistry, as the introduction of fluorine atom (s) onto molecules would modify considerably their chemical and physicochemical properties ${ }^{1-6}$. Thus, methods for the synthesis of organofluorine compounds have been flourished in both profundity and scope $\mathrm{e}^{7-13}$. The difluoromethyl group $\left(\mathrm{CF}_{2} \mathrm{H}\right)$, as an analogue of the well-known trifluoromethyl group $\left(\mathrm{CF}_{3}\right)$, has recently received increasing attentions and many powerful methods for its introduction into organic compounds have been developed ${ }^{14-19}$. On the other hand, allenes are key intermediates in organic synthesis and are important structural motifs that can also be found in natural products ${ }^{20-24}$. For the purpose of providing diverse fluorinated molecules to meet the increasing demand for drug discovery and new materials development, methods for efficient synthesis of various fluorinated or fluoroalkylated allenes are evidently of great value, as such allenes allow a great number of valuable skeletal and stereochemical transformations ${ }^{21,24}$.

Over the past few decades, many difluoromethylation reactions have been successfully developed, enabling facile synthesis of different types of difluoromethylated compounds. Most commonly, the $\mathrm{CF}_{2} \mathrm{H}$ group (or $\mathrm{CF}_{2} \mathrm{R}$ group) is accessed from a $\mathrm{CF}_{2^{-}}$ containing building block or agent ${ }^{14-19,25-31}$. For example, the syntheses of difluoromethylated allenes typically require the use of difluoromethyl metal compounds ${ }^{32-35}$. Recently, Wang et al. developed the nickel-catalyzed carbofluoroalkylation affording difluoroalkylated allenes using ethyl bromodifluoroacetate ${ }^{36}$. Notwithstanding these significant breakthroughs, the development of efficient and diversified approaches for the facile construction of difluoromethylated allenes is still challenging especially starts from non- $\mathrm{CF}_{2}$-containing building blocks and methods for the synthesis of difluoroalkylated allenes are still demanded.

Inspired by earlier reports on gem-difluorination (Fig. 1a) ${ }^{37-40}$

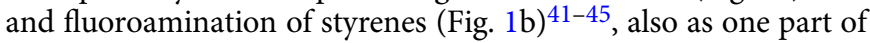
our continuous efforts on functionalization of unsaturated compounds ${ }^{46-49}$, herein, we report a metal-free consecutive trifunctionalization of 1,3-enynes for the assembly of various difluoromethylated allenyl amines (Fig. 1c) using NFSI as the fluorination and amination source $41,44,50-59$. The synthetic potential of difluoromethylated allenes is demonstrated by transformations to a variety of difluoromethylated compounds ${ }^{21}$.

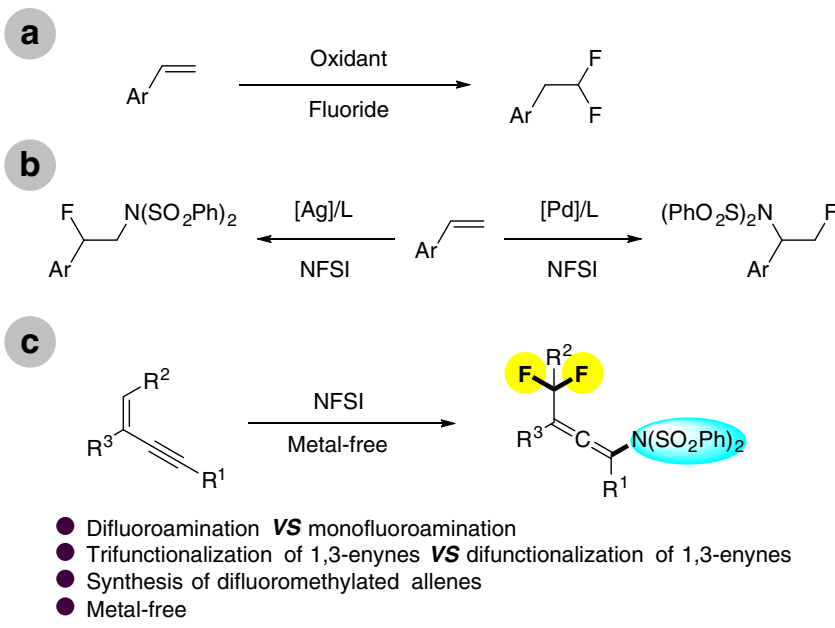

Fig. 1 Fluorination or difluorination of $\mathbf{C}=\mathbf{C}$ bonds. a $\mathrm{Gem}$-difluorination of styrenes. b Fluoroamination of styrenes. c This work: facile synthesis of difluoromethylated allenes.

\section{Results}

Reaction optimization. We commenced reaction condition optimization using CuTC as the catalyst and 1,10-phenanthroline as the ligand. As shown in Table 1, the reaction between 1,3enyne 1a and NFSI was originally thought to involve intermolecular 1,4-fluoroamination, providing the monofluoromethylated allene $\mathbf{3} \mathbf{a}$ as the desired product ${ }^{49}$. However, only a trace amount of $\mathbf{3} \mathbf{a}$ was detected, and a new compound, the difluoromethylated allene $\mathbf{4 a}$, was obtained as major product albeit in a low yield (Table 1, entry 1). Formation of the product 4a alluded to a previously unknown reaction, and we therefore decided to optimize the conditions towards formation of 4a. With the $\mathrm{Pd}(\mathrm{OAc})_{2} / \mathrm{BC}$ catalyst system ${ }^{45}$, product $\mathbf{4 a}$ was obtained in $34 \%$ yield (Table 1 , entry 2 ). Use of a $\mathrm{CoCl}_{2}$ catalyst failed to provide any targeted $4 \mathbf{a}$ (Table 1 , entry 4 ), while $\mathrm{Pt}(\mathrm{COD}) \mathrm{Cl}_{2}$ and $\mathrm{NiCl}_{2}$ showed a better performance than the $\mathrm{Pd}(\mathrm{OAc})_{2} / \mathrm{BC}$ catalyst system (Table 1 , entry $5 \mathrm{v}$. entry $6 \mathrm{v}$. entry 2 ). After extensive screening experiments, it was found that the reaction of the 1,3enyne 1a with NFSI afforded $4 \mathbf{a}$ in $28 \%$ yield, even in the absence of catalyst and ligand (Table 1, entry 7). The yield of $\mathbf{4 a}$ was further improved to $44 \%$ upon running the reaction at an elevated temperature (Table 1, entry 8). Other solvents were screened and it was found that toluene and chloroform provide the product $4 \mathrm{a}$ in 66 and $61 \%$ yield (Table 1, entries 9 and 10), while acetonitrile, a polar solvent, afforded the targeted product in only $12 \%$ yield (Table 1 , entry 11 ). Furthermore, the yield of $4 a$ dropped when the reaction was carried out in toluene at $100^{\circ} \mathrm{C}$ (Table 1 , entry 12). Notably, a small amount of the monofluoromethylated allene $\mathbf{3 a}$ was observed in all these reactions.

Substrate scope. With the optimal reaction conditions in hand, the substrate scope was studied and various difluoromethylated allenes were successfully prepared in moderate to good yields. As shown in Fig. 2, the phenyl group at position 2 can be replaced by a substituted phenyl group (4b-4v). Electron-donating groups on the benzene ring, such as a methyl group, an iso-butyl group, or a tert-butyl group, and electron-withdrawing substituents such as $\mathrm{Br}, \mathrm{F}$, and $\mathrm{CN}$ on the benzene ring are tolerated. Enynes with primary, secondary, or tertiary alkyl groups linked with the $\mathrm{C}-\mathrm{C}$ triple bond could also be diversified. As examples, 1,3-enynes with a $n$-hexyl group (1b-1i), a cyclopropyl group (1k, 11, and $\mathbf{1 n}$ ), a chloroalkyl group (1m), or a tert-butyl group (10) are suitable substrates for the direct difluoroamination reaction. 1,3Enynes bearing a silyl group (1r), a silyl ether moiety (1s), or an ester group (1t) also engage in this reaction. Moreover, 2,4-diaryl substituted 1,3-enynes can be used as the substrates to afford the corresponding products in moderate yields (see $\mathbf{4 u}$ and $\mathbf{4 v}$ ). However, (3-methylbut-3-en-1-yn-1-yl)benzene (1w), as an example for non-styrene systems, only provided the desired product $\mathbf{4 w}$ in $24 \%$ yield, which might be due to the less stability of the intermediate compared to that of 1-alkynyl styrenes. The structures of the difluoromethylated allenes $4 \mathbf{k}$ and $4 \mathbf{l}$ were unambiguously confirmed by single crystal X-ray diffraction.

Encouraged by the results using terminal 1,3-enynes, we next investigated difluoroamination of internal 1,3-enynes aiming at the preparation of difluoroalkylated allenes. With 1,3-enyne $\mathbf{1 x}$, bearing a primary alkyl group linked with the $\mathrm{C}-\mathrm{C}$ triple bond, only a $28 \%$ yield of the product $4 \mathbf{x}$ was obtained, and the accompanying monofluoroamination product $3 \mathbf{x}$ was produced in $46 \%$ yield as major compound. However, it was found that the substrates bearing a bulky group at the triple bond deliver the corresponding products $\mathbf{4 y - 4 a e ~ i n ~ h i g h e r ~ y i e l d s ~ a n d ~ f u n c t i o n a l - ~}$ ities such as the ester group (4ac) and silyl groups (4ad and 4ae) are tolerated. 
Table 1 Reaction condition optimization.

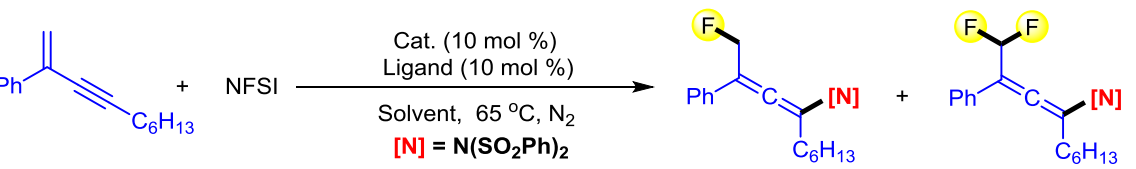

1a $\quad 2 \quad 3 a \quad 4 a$

\begin{tabular}{|c|c|c|c|c|}
\hline Entry & Cat. & Ligand & Solvent & Yield of $4 a(\%)^{a}$ \\
\hline 1 & CuTC & 1,10-Phen & DCM & $<5$ \\
\hline 2 & $\mathrm{Pd}(\mathrm{OAc})_{2}$ & $\mathrm{BC}$ & DCM & 34 \\
\hline 3 & $\mathrm{PdCl}_{2}$ & 1,10-Phen & DCM & 24 \\
\hline 4 & $\mathrm{CoCl}_{2}$ & 1,10-Phen & DCM & trace \\
\hline 5 & $\mathrm{Pt}(\mathrm{COD}) \mathrm{Cl}_{2}$ & 1,10-Phen & DCM & 40 \\
\hline 6 & $\mathrm{NiCl}_{2}$ & 1,10-Phen & DCM & 48 \\
\hline 7 & - & - & DCM & $28^{b}$ \\
\hline 8 & - & - & DCM & $44^{c}$ \\
\hline 9 & - & - & toluene & $66^{c}(65)^{d}, e$ \\
\hline 10 & - & - & $\mathrm{CHCl}_{3}$ & $61^{c}$ \\
\hline 11 & - & - & $\mathrm{CH}_{3} \mathrm{CN}$ & $12^{\mathrm{c}}$ \\
\hline 12 & - & - & toluene & $51^{f}$ \\
\hline
\end{tabular}

Reaction conditions: 1,3-enyne (1a, $0.25 \mathrm{mmol}), \mathrm{NFSI}(0.75 \mathrm{mmol})$, cat $(10 \mathrm{~mol} \%)$, ligand $(10 \mathrm{~mol} \%)$, solvent $(0.5 \mathrm{~mL}), 65^{\circ} \mathrm{C}, \mathrm{under}$ a $\mathrm{N}_{2}$ atmosphere

1,10-Phen 1,10-phenanthroline, $B C$ bathocuproine

1,10-Phen $1,10-p h e n$
al $\mathrm{H}$ NMR yield

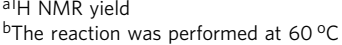

CThe reaction was performed at $80^{\circ} \mathrm{C}$

disolated yield in parentheses

eThe ${ }^{1} \mathrm{H}$ NMR yield of $\mathbf{3 a}$ is $8 \%$

fThe reaction was performed at $100^{\circ} \mathrm{C}$

Synthetic applications. Synthetic applications of this consecutive difluoroamination of 1,3-enynes have been demonstrated and are shown in Fig. 3. In the presence of $N$-iodosuccinimide (NIS), the difluoromethylated allene $\mathbf{4 m}$ was regioselectively transformed into the $(Z, Z)$-diene 5 in $54 \%$ yield. Note that during iodination one of the sulfonyl groups of the $-\mathrm{N}\left(\mathrm{SO}_{2} \mathrm{Ph}\right)_{2}$ functionality was removed. Interestingly, when the allene $\mathbf{4 u}$ bearing two phenyl groups was subjected to the reaction with NIS, the difluoromethylated vinyl imine $\mathbf{6}$ was formed. Such vinyl iodides, 5 and 6, are also pivotal building blocks for further transformations ${ }^{60}$. Moreover, the silyl group of the allene $4 \mathrm{~s}$ could be readily removed to afford the allene 7 with a free alcohol group (81\%), which could be further cyclized in $57 \%$ yield to the multisubstituted 3,6-dihydro-2H-pyran 8.

Mechanistic studies. Finally, preliminary experiments to probe the mechanism of the difluoromethylated allene formation reaction were performed. Since the fluoroamination product $\mathbf{3 a}$ was found as a side product (see Table 1), 3a was supposed to be the reaction intermediate and was therefore subjected to the standard conditions. However, the desired product $\mathbf{4 a}$ was not detected (Fig. 4a). Notably, during reaction optimization the fluorinated 1,3-enyne ${ }^{61-68} 9$ a was observed. In addition, treatment of the 1,3enyne 1a with a reduced amount of NFSI afforded compound 9a along with targeted $\mathbf{4 a}$. Therefore, we suspected that 9a might be a key intermediate in this cascade. Indeed, when compound 9a was subjected to the reaction with NFSI, product $4 a$ was isolated in $74 \%$ yield (Fig. 4 b), suggesting that $\mathbf{9 a}$, rather than $\mathbf{3 a}$, is a possible intermediate for the difluoroamination and this reaction probably relies on a two-step process.

DFT study. On the other hand, DFT study was also performed according to the experiments of mechanism studies. Initially, three kinds of 1,3-enyne radical cation species oxidized by NFSI were considered, but the enthalpies were too high $(\Delta \mathrm{H}>57 \mathrm{kcal} / \mathrm{mol})$ to support the cation radical process (Supplementary Fig. 1) ${ }^{44}$.

We then focus on the allenyl cation pathways. Two-component reactions of an 1,3-enyne with NFSI were investigated in different orientations of NFSI to transfer the fluoride to 1,3-enyne, $\mathbf{1}$. Two transition states, TS1 and TS1', were located leading to the reactive intermediate 9 with a dibenzenesulfonimide (DBSI) moiety synchronously and the 1,2-adduct $N$-(1-fluoro-2-phenylhept-3-yn-2-yl)- $N$-(phenylsulfonyl)benzenesulfonamide (10), with activation free energy of 25.1 and $31.1 \mathrm{kcal} / \mathrm{mol}$, respectively (Supplementary Fig. 2), in which producing DBSI via TS1 is a concerted process after fluorine transfer. Intrinsic reaction coordinate (IRC) calculations have been conducted for the validity of concerted proton transfer and 1,2-addition from TS1 and TS1', respectively (Supplementary Figs. 3 and 4). In addition, TS6, the transition state corresponding to the bisphenylsulfonyl imide moiety of NFSI directly addition to the $4 \mathrm{C}$ atom of $\mathbf{1}$, was calculated as well. However, the activation energy of TS6 is so much higher $(59.4 \mathrm{kcal} / \mathrm{mol})$, and it results in a 3,4-addition compound $\mathrm{N}$-(3-fluoro-2-phenylhepta-1,3-dien-4-yl)- $\mathrm{N}$-(phenylsulfonyl)benzenesulfonamide (11) (Supplementary Fig. 2) which was confirmed by IRC calculation as well as the calculations from TS1 and TS1'. It is worth noting that no transition state corresponding to 1,4-addition to form desired product 4 can be located. This is reasonable because the bond distance of N-F of the optimized NFSI molecule is $1.40 \AA$ much less than the distance between $1 \mathrm{C}$ and $4 \mathrm{C}$ in the optimized structure of $1(d(1 C-4 C)=3.54 \AA)$.

Since the product ( $N$-(1,1-difluoro-2-phenyldeca-2,3-dien-4yl)-4-methyl- $N$-tosylbenzenesulfonamide, 12) adducted by $\mathrm{N}$ (Ts) $)_{2}$ can be observed in presence of the $\mathrm{HN}(\mathrm{Ts})_{2}$ (see crossover reaction in Supplementary Methods), three-component reactions of 1,3-enyne with NFSI and DBSI were further considered and discussed. Figure 5 shows the overall potential energy surface from 1 to produce the 1,4-addition major product 4 and minor product 3. As described above, 1 reacts with NFSI first to form 


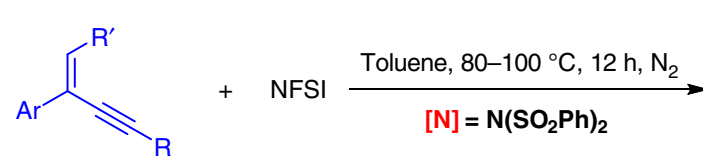

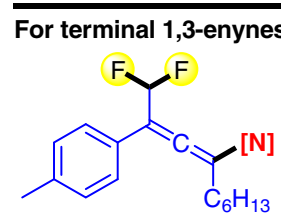

4b, $62 \%$<smiles>CCCCCCC(=C=C(c1ccc(C(C)(C)C)cc1)C(F)F)C#N</smiles>

4f, $62 \%$<smiles>CCCC([N])=C=C(c1ccccc1C)C(F)F</smiles>

4c, $62 \%$

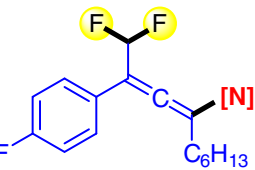

4g, $50 \%$<smiles>C=C=C([N])C(=C=C(CCCCCC)C(F)F)c1cc(C)cc(C)c1</smiles>

4d, $52 \%$<smiles>NC(=C=C(c1ccc(Br)cc1)C(F)F)C(=O)O</smiles>

4 e, $53 \%$<smiles>NC(CCCCC(N)C(F)(F)F)=C(c1ccc(Br)cc1)C(F)F</smiles>

4h, $44 \%$<smiles>NC(=O)C(N)=C=C(c1ccc(F)cc1)C(F)F</smiles>

$4 \mathrm{i}, 20 \%$<smiles>C=C([NH3+])C=C(c1ccc(C)cc1)C(F)F</smiles>

$4 \mathrm{j}, 51 \%$<smiles>NC(=C=C(c1ccc(Cl)cc1)C(F)F)C1CC1</smiles>

4I, $44 \%$

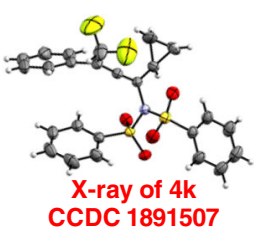<smiles>CCC(N)=C(c1ccc(C)cc1)C(F)F</smiles>

$4 \mathrm{~m}, 46 \%$

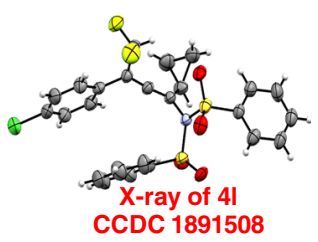<smiles>Cc1ccc(C(=C(N)C(F)F)C(C)C)cc1</smiles>

4n, $52 \%$

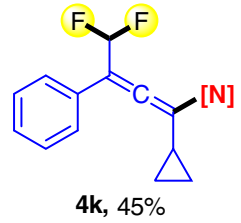

$\mathbf{4 k}, 45 \%$<smiles>Cc1ccc(C(=C=C(N)CCl)C(F)F)cc1</smiles>

4p, $57 \%$<smiles>CCCCC(=C=C(c1ccc(C)cc1)C(F)F)C(=N)N</smiles>

4q, $52 \%$<smiles>Cc1ccc(C(=C=C(N)[NH3+])C(F)F)cc1</smiles>

4r, $44 \%$<smiles>Cc1ccc(C(=C=C(N)C(C)(C)C)C(F)F)cc1</smiles>

4o, $53 \%$<smiles>CCCCC(=C=C(c1ccccc1)C(F)F)C(N)=C=[W]</smiles><smiles>N#CC(=C=C(c1ccccc1)C(F)F)c1ccccc1</smiles>

4u, 54\%<smiles></smiles>

4v, $46 \%$<smiles>NC(=C=C(c1ccccc1)C(F)F)CO[18OH]</smiles>

4s, $53 \%$<smiles>CC(=C=C([N])Pc1ccccc1)C(F)F</smiles>

4w, 24\%<smiles>CC(F)(F)C(=C=C([NH])N)c1ccccc1</smiles>

$4 x, 28 \%$ b<smiles>CCC(F)(F)C(=C=C([N])C(C)(C)C)c1ccccc1</smiles>

4ab, $74 \%$<smiles>CC(C)(C)C(=C=C(c1ccccc1)C(C)(C)F)C(C)(C)C</smiles>

4y, $80 \%$<smiles>COC(=O)CCC(F)(F)C(=C=C([N])C(C)(C)C)c1ccccc1</smiles>

4ac, $61 \%$<smiles>CC(C)(C)C(N)=C=C(c1ccc(F)cc1)C(C)(C)F</smiles>

4z, $83 \%$<smiles>CC(C)(C)C(=C=C(c1ccccc1)C(C)(F)F)N=[W]</smiles>

4ad, $63 \%$<smiles>CC(C)(C)C(=C=C(c1ccc(Cl)cc1)C(C)(C)F)C(C)(N)C(C)(C)C</smiles>

4aa, $74 \%$<smiles>CC(F)(F)C(=C=C([AlH2])[AlH](F)(F)F)c1ccccc1</smiles>

4ae, $42 \%$

Fig. 2 Substrate scope of 1,3-enynes. Reaction conditions: 1,3-enyne (1, $0.5 \mathrm{mmol}), \mathrm{NFSI}(1.5 \mathrm{mmol})$, toluene $(1 \mathrm{~mL}), 80-100{ }^{\circ} \mathrm{C}, \mathrm{N}_{2}$ atmosphere, Isolated yield. aWith $\mathrm{CHCl}_{3}(1 \mathrm{~mL})$ as the solvent. bThe reaction was performed in cyclohexane and the monofluoromethylated allene $\mathbf{3} \mathbf{x}$ was obtained in $46 \%$ yield. 
a<smiles>Cc1ccc(C(=C=C(CCCCl)NS(=O)(=O)O)C(F)F)cc1</smiles>

$4 m$

b<smiles>O=S(=O)(Oc1ccccc1)N(C(=C=C(c1ccccc1)C(F)F)c1ccccc1)c1ccccc1</smiles>

$4 u$

$4 \mathrm{~s}$<smiles></smiles>

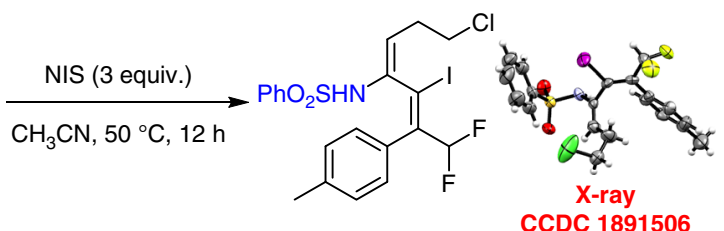

5, $54 \%$

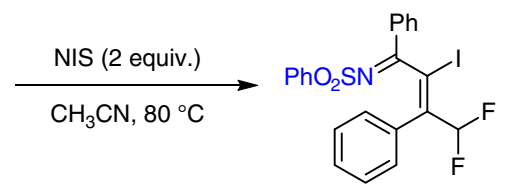

$6,50 \%$

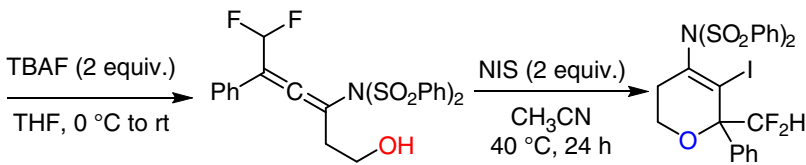

$7,81 \%$

8, $57 \%$

Fig. 3 Synthetic applications. a Derivatizations of difluoromethylated allene $\mathbf{4 m}$. b Derivatizations of difluoromethylated allene $\mathbf{4 u}$. c Synthesis of multisubstituted 3,6-dihydro-2H-pyran $\mathbf{8}$ from difluoromethylated allene $\mathbf{4 s}$.

the reactive intermediate 9 with the DBSI through the lowest energetic transition state TS1. Then, the reactive intermediate 9 reacts with a second NFSI to form an ion pair of difluoromethylallenyl cation and bisphenylsulfonyl imide anion (int1) through TS2 with the energy barrier of $25.5 \mathrm{kcal} / \mathrm{mol}$. Subsequently, an adjacent DBSI, generated from the first step, participates in the reaction to suspend the 2 -addition of bisphenylsulfonyl imide anion to difluoromethylallenyl cation. A low barrier transition state TS3 $(13.9 \mathrm{kcal} / \mathrm{mol})$ corresponding to simultaneous imide addition-proton transfer was then located to form the product 4 and to regenerate a DBSI.

On the other hand, the pathway of three-component reaction combining 1 and NFSI with DBSI to deliver the minor product 3 was also calculated. A three-component transition state of fluorine transfer, TS4, was located with the energy barrier of $29.0 \mathrm{kcal} / \mathrm{mol}$ which is higher than that of TS1 but lower than that of TS1'. As expectation, an intermediate int3 was then conducted similar to int 2 in which the DBSI suspends the proton abstraction and the 2-addition of bisphenylsulfonyl imide anion. Subsequently, transition state TS5 corresponding to simultaneous imide addition-proton transfer can also be located with $11.7 \mathrm{kcal} /$ mol of barrier resulting in the monofluoroamination product 3 and regenerating a DBSI. It is noteworthy that the barrier of TS4, $3.9 \mathrm{kcal} / \mathrm{mol}$ higher than that of TS1, may be somewhat too high to compete with the path of $\mathbf{9}$ generation due to the artificial overestimation of unfavorable DBSI association entropy, as seen in comparison with the energy difference between int 1 and int2. Nevertheless, according to the crossover reaction, the proposed trimolecular pathway with higher barrier to form the side product 3 is believed to take place in the reactions.

Kinetic studies. For further supporting this hypothesis, kinetic studies of the reaction was therefore conducted to track the formations of side product 3 , major product $\mathbf{4}$ and active intermediate 9 (Supplementary Fig. 5). Because of lacking 9 and DBSI, the induction period of formation of $\mathbf{3}$ and $\mathbf{4}$ should thus be seen if the trimolecular pathway is the favorable one. Figure 6 presents the kinetic profiles for the formations of $3 \mathbf{a}, \mathbf{4 a}$ and $9 \mathbf{a}$.

As expected, the reaction rate of $\mathbf{9 a}$ is faster than that of $\mathbf{3 a}$, and the induction period of $\mathbf{3} \mathbf{a}$ and $\mathbf{4 a}$ can be observed. Initially, even no

a<smiles>O=C(O)N(C(=C=C(CF)c1ccccc1)c1ccccc1)S(=O)(=O)O</smiles>

3a

b<smiles>F/C=C(\C#CCc1ccccc1)c1ccccc1</smiles>

9a

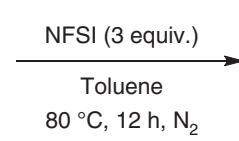

$80^{\circ} \mathrm{C}, 12 \mathrm{~h}, \mathrm{~N}_{2}$

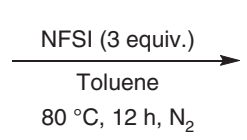

$80^{\circ} \mathrm{C}, 12 \mathrm{~h}, \mathrm{~N}_{2}$

a Test of $\mathbf{3} \mathbf{a}$ as the possible reactive intermediate. $\mathbf{b}$ Test of $\mathbf{9 a}$ as the possible reactive intermediate.

trace amount of $3 \mathbf{a}$ and $4 \mathbf{a}$ can be detected in the first 6 minutes. After that, trace amounts of $\mathbf{3 a}$ can be observed, but the rate of generation is very slow; nevertheless, the yield of 9a has been over $10 \%$ at the 20 minute. Although the yields of $\mathbf{3 a}$ and $\mathbf{4 a}$ are almost the same in the first one hour, the generation rate of $\mathbf{4 a}$ seems to accelerate probably due to the increase of concentration of 9 a. Finally, the active intermediate $\mathbf{9 a}$ is consumed to deliver the major product $\mathbf{4 a}$ at the end of reaction, and the amounts of $\mathbf{3} \mathbf{a}$ should stop to grow after expending all of the reactant 1a. The fast generation rate of $\mathbf{9}$ and the induction periods of formations of 3 and $\mathbf{4}$ are well consistent with the proposed reaction mechanism.

Proposed mechanism. Based on our mechanistic experiments, theoretical studies and published work ${ }^{41,44,45,69,70}$, the proposed mechanism for the synthesis of difluoromethylated allenes from trifunctionalization of 1,3-enynes is depicted in Fig. 7. Initially, electrophilic fluorination of the 1,3-enyne $\mathbf{1}$ by NFSI synchronously generates the dibenzenesulfonimide and the fluorinated enyne 9 as the reactive intermediate. The second NFSI then reacts with 9 to afford the major product 4 assisted by the DBSI, adjacent to 9 . On the other hand, accumulation of DBSI will aid the formation of fluorination product 3 , which is observed as a 


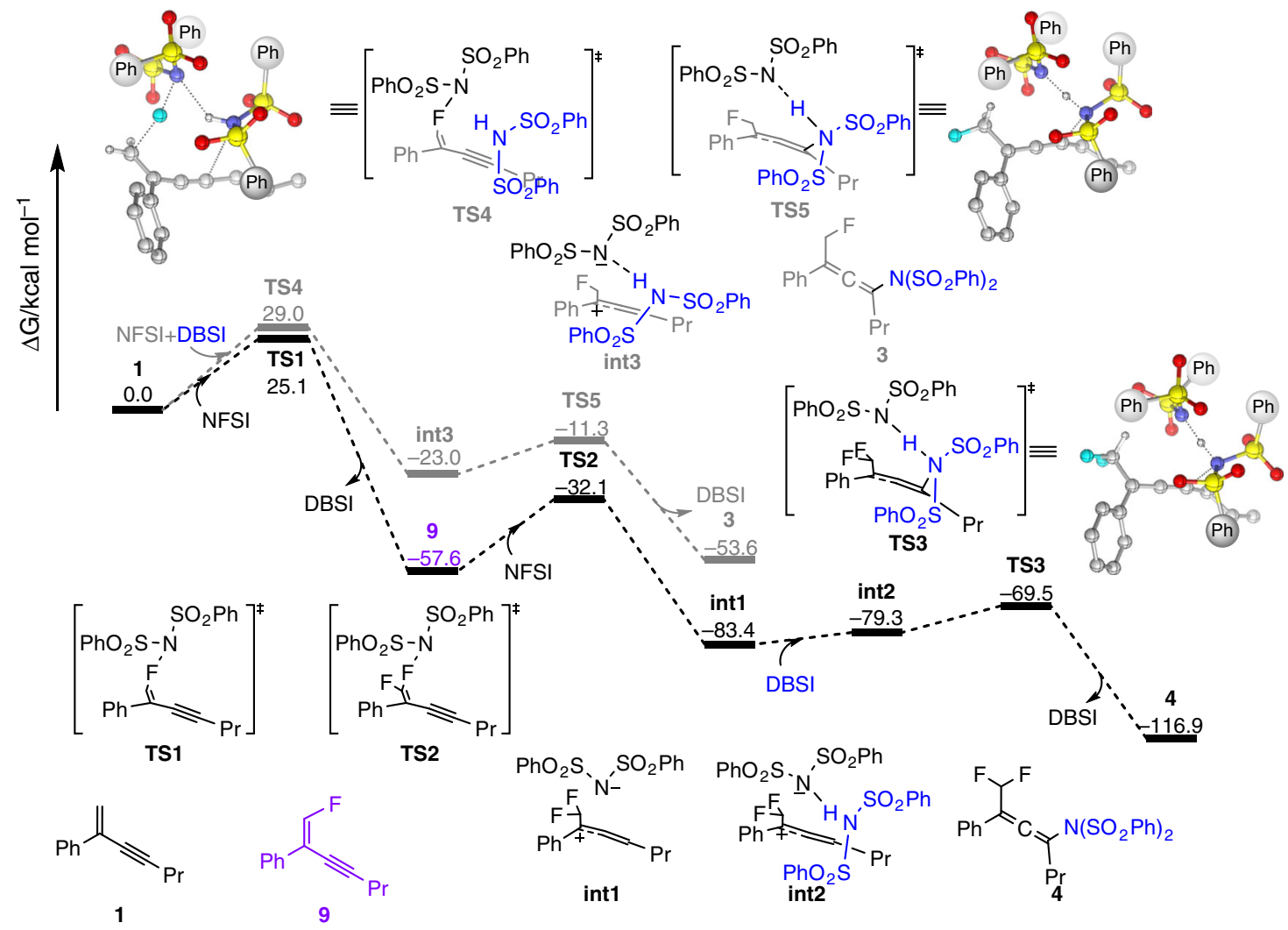

Fig. 5 DFT study. The free energy profile of formations of fluoroamination and difluoroamination products, 3 and 4.

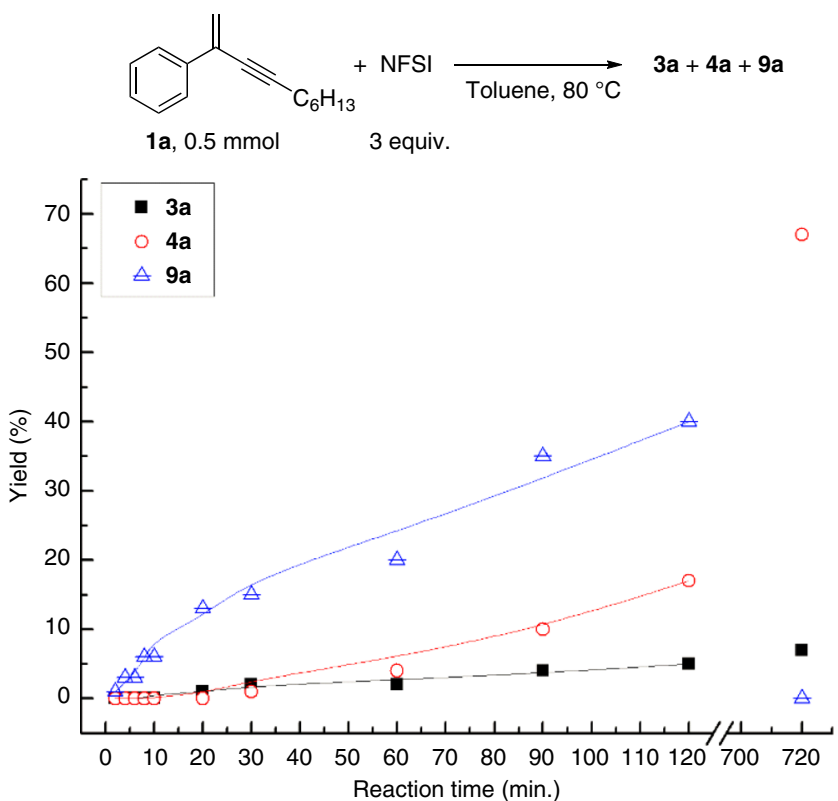

Fig. 6 Kinetic studies. Kinetic profiles for the formation of $\mathbf{3 a}, \mathbf{4 a}$ and active intermediate $\mathbf{9 a}$.

side product cannot be converted into product 4 under the standard reaction conditions. The surplus DBSI can also assists the NFSI to react with the substrate $\mathbf{1}$ to form the side product 3.

In conclusion, a metal-free synthesis of various difluoromethylated allenes through difluoroamination of 1,3-enynes has been developed. NFSI was used as the reactant and a broad substrate scope was obtained. The synthetic potential of difluoromethylated

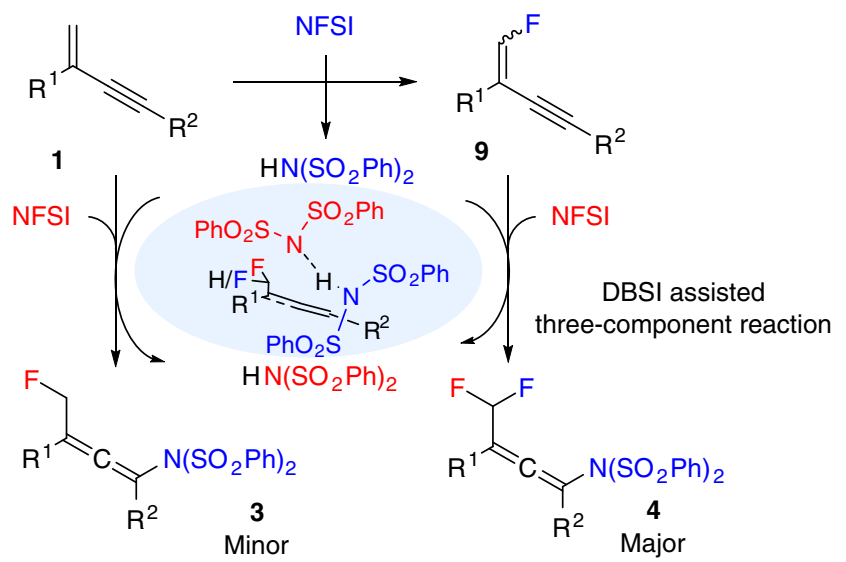

Fig. 7 Proposed reaction mechanism. Dibenzenesulfonimide assisted three-component trifunctionalization of 1,3-enynes.

allenes has been demonstrated by transformations of them to a variety of useful difluoromethylated compounds. Moreover, this reaction is also a rare example of trifunctionalization of 1,3-enynes. Preliminary mechanistic studies suggest that a two-step pathway is involved and DFT studies revealed a dibenzenesulfonimide-assisted fluorination/fluoroamination with NFSI.

\section{Methods}

General procedure. In a flame-dried Schlenk tube, NFSI ( $1.5 \mathrm{mmol}, 3.0$ equiv.) was dissolved in toluene $(1 \mathrm{~mL})$ under a nitrogen atmosphere. Then, 1,3-enyne $\left(0.5 \mathrm{mmol}, 1.0\right.$ equiv.) was added. The reaction mixture was stirred at $80^{\circ} \mathrm{C}$ for 12 h. After the reaction completion as detected by TLC, the solvent was evaporated under reduced pressure. The residue was purified by flash column chromatography on silica gel (PE/EA or PE/DCM) to afford the allene product. 


\section{Data availability}

Detailed experimental procedures and characterization of compounds can be found in the Supplementary Information. The X-ray crystallographic coordinates for structures reported in this article have been deposited at the Cambridge Crystallographic Data Center (4k: CCDC 1891507; 4l: CCDC 1891508; 5: CCDC 1891506). These data could be obtained free of charge from The Cambridge Crystallographic Data Center via www.ccdc. cam.ac.uk/data_request/cif. All data are available from the authors upon request.

Received: 10 May 2019; Accepted: 19 December 2019;

Published online: 21 January 2020

\section{References}

1. Hiyama, T. Organofluorine Compounds: Chemistry and Applications. (Springer, 2000).

2. Ojima, I. (ed) Fluorine in Medicinal Chemistry and Chemical Biology. (WileyBlackwell, 2009).

3. Kirsch, P. Modern Fluoroorganic Chemistry. (Wiley-VCH, 2013).

4. Muller, K., Faeh, C. \& Diederich, F. Fluorine in pharmaceuticals: looking beyond intuition. Science 317, 1881-1886 (2007).

5. Purser, S., Moore, P. R., Swallow, S. \& Gouverneur, V. Fluorine in medicinal chemistry. Chem. Soc. Rev. 37, 320-330 (2008)

6. Zhou, Y. et al. Next generation of fluorine-containing pharmaceuticals, compounds currently in phase II-III clinical trials of major pharmaceutical companies: new structural trends and therapeutic areas. Chem. Rev. 116, 422-518 (2016).

7. Besset, T., Poisson, T. \& Pannecoucke, X. Recent progress in direct introduction of fluorinated groups on alkenes and alkynes by means of $\mathrm{C}-\mathrm{H}$ bond functionalization. Chem. Eur. J. 20, 16830-16845 (2014).

8. Charpentier, J., Fruh, N. \& Togni, A. Electrophilic trifluoromethylation by use of hypervalent iodine reagents. Chem. Rev. 115, 650-682 (2015).

9. Liang, T., Neumann, C. N. \& Ritter, T. Introduction of fluorine and fluorinecontaining functional groups. Angew. Chem. Int. Ed. 52, 8214-8264 (2013).

10. Gao, P., Song, X.-R., Liu, X.-Y. \& Liang, Y.-M. Recent developments in the trifluoromethylation of alkynes. Chem. Eur. J. 21, 7648-7661 (2015).

11. Merino, E. \& Nevado, C. Addition of $\mathrm{CF}_{3}$ across unsaturated moieties: a powerful functionalization tool. Chem. Soc. Rev. 43, 6598-6608 (2014).

12. $\mathrm{Ni}, \mathrm{C} . \& \mathrm{Hu}, \mathrm{J}$. The unique fluorine effects in organic reactions: recent facts and insights into fluoroalkylations. Chem. Soc. Rev. 45, 5441-5454 (2016).

13. Tomashenko, O. A. \& Grushin, V. V. Aromatic trifluoromethylation with metal complexes. Chem. Rev. 111, 4475-4521 (2011).

14. Belhomme, M.-C., Besset, T., Poisson, T. \& Pannecoucke, X. Recent progress toward the introduction of functionalized difluoromethylated building blocks onto $\mathrm{C}\left(\mathrm{sp}^{2}\right)$ and $\mathrm{C}(\mathrm{sp})$ centers. Chem. Eur. J. 21, 12836-12865 (2015).

15. Feng, Z., Xiao, Y.-L. \& Zhang, X. Transition-metal (Cu, Pd, Ni)-catalyzed difluoroalkylation via cross-coupling with difluoroalkyl halides. Acc. Chem. Res. 51, 2264-2278 (2018).

16. Hu, J., Zhang, W. \& Wang, F. Selective difluoromethylation and monofluoromethylation reactions. Chem. Commun. 45, 7465-7478 (2009).

17. Landelle, G. et al. Recent advances in transition metal-catalyzed $\operatorname{Csp}(2)$ monofluoro-, difluoro-, perfluoromethylation and trifluoromethylthiolation. Beilstein J. Org. Chem. 9, 2476-2536 (2013).

18. Rong, J., Ni, C. \& Hu, J. Metal-catalyzed direct difluoromethylation reactions. Asian J. Org. Chem. 6, 139-152 (2017).

19. Yerien, D. E., Barata-Vallejo, S. \& Postigo, A. Difluoromethylation Reactions of Organic compounds. Chem. Eur. J. 23, 14676-14701 (2017).

20. Hoffmann-Röder, A. \& Krause, N. Synthesis and properties of allenic natural products and pharmaceuticals. Angew. Chem. Int. Ed. 43, 1196-1216 (2004).

21. Ma, S. Some typical advances in the synthetic applications of allenes. Chem. Rev. 105, 2829-2872 (2005).

22. Brummond, K. M. \& DeForrest, J. E. Synthesizing allenes today (1982-2006). Synthesis 2007, 795-818 (2007).

23. Aubert, C. et al. Transition metal catalyzed cycloisomerizations of 1,nAllenynes and -Allenenes. Chem. Rev. 111, 1954-1993 (2011).

24. Ma, S. Electrophilic addition and cyclization reactions of allenes. Acc. Chem. Res. 42, 1679-1688 (2009).

25. Cao, P., Duan, J.-X. \& Chen, Q.-Y. Difluoroiodomethane: practical synthesis and reaction with alkenes. J. Chem. Soc., Chem. Commun. 737-738 (1994).

26. Xia, J.-B., Zhu, C. \& Chen, C. Visible light-promoted metal-free C-H activation: diarylketone-catalyzed selective benzylic mono- and difluorination. J. Am. Chem. Soc. 135, 17494-17500 (2013).

27. Tang, X.-J. \& Dolbier, W. R. Jr. Efficient Cu-catalyzed atom transfer radical addition reactions of fluoroalkylsulfonyl chlorides with electrondeficient alkenes induced by visible light. Angew. Chem. Int. Ed. 54, 4246-4249 (2015).
28. Lin, Q.-Y., Ran, Y., Xu, X.-H. \& Qing, F.-L. Photoredox-catalyzed bromodifluoromethylation of alkenes with (difluoromethyl) triphenylphosphonium bromide. Org. Lett. 18, 2419-2422 (2016).

29. Arai, Y. et al. Oxydifluoromethylation of alkenes by photoredox catalysis: simple synthesis of $\mathrm{CF}_{2} \mathrm{H}$-containing alcohols. Chem. Eur. J. 22, 1262-1265 (2016).

30. Zhang, M., Lin, J. H. \& Xiao, J. C. Photocatalyzed cyanodifluoromethylation of alkenes. Angew. Chem. Int. Ed. 58, 6079-6083 (2019).

31. Testa, C. et al. Palladium-catalysed $\mathrm{C}-\mathrm{H}$ bond electrophilic fluorination of highly substituted arylpyrazoles: experimental and DFT mechanistic insights. Adv. Synth. Catal. 357, 2913-2923 (2015).

32. Burton, D. J. \& Hartgraves, G. A. Regioselective preparation of difluoromethyl allenes. J. Fluor. Chem. 49, 155-158 (1990).

33. Burton, D. J., Hartgraves, G. A. \& Hsu, J. A facile, general route to perfluoroalkyl allenes. Tetrahedron Lett. 31, 3699-3702 (1990).

34. Burton, D. J. \& Hartgraves, G. A. The preparation of $\mathrm{HCF}_{2} \mathrm{CdX}$ and $\mathrm{HCF}_{2} \mathrm{ZnX}$ via direct insertion into the carbon halogen bond of $\mathrm{CF}_{2} \mathrm{HY}(\mathrm{Y}=\mathrm{Br}, \mathrm{I}) . J$. Fluor. Chem. 128, 1198-1215 (2007).

35. Gu, Y., Lu, C., Gu, Y. \& Shen, Q. Ligand-controlled copper-catalyzed highly regioselective difluoromethylation of allylic chlorides/bromides and propargyl bromides. Chin. J. Chem. 36, 55-58 (2018).

36. Zhang, K.-F. et al. Nickel-catalyzed carbofluoroalkylation of 1,3-enynes to access structurally diverse fluoroalkylated allenes. Angew. Chem. Int. Ed. 58, 5069-5074 (2019).

37. Banik, S. M., Medley, J. W. \& Jacobsen, E. N. Catalytic, asymmetric difluorination of alkenes to generate difluoromethylated stereocenters. Science 353, 51-54 (2016)

38. Ilchenko, N. O., Tasch, B. O. A. \& Szabo, K. J. Mild silver-mediated geminal difluorination of styrenes using an air- and moisture-stable fluoroiodane reagent. Angew. Chem. Int. Ed. 53, 12897-12901 (2014).

39. Kitamura, T., Muta, K. \& Oyamada, J. Hypervalent iodine-mediated fluorination of styrene derivatives: stoichiometric and catalytic transformation to 2,2-difluoroethylarenes. J. Org. Chem. 80, 10431-10436 (2015).

40. Scheidt, F. et al. Catalytic geminal difluorination of styrenes for the construction of fluorine-rich bioisosteres. Org. Lett. 20, 8073-8076 (2018).

41. Zhang, H. et al. Regioselective radical aminofluorination of styrenes. Angew. Chem. Int. Ed. 53, 11079-11083 (2014).

42. Zhang, Q. \& Li, Y. N-Fluorobenzenesulfonimide: an efficient nitrogen source for C-N bond formation. Synthesis 47, 159-174 (2014).

43. Xiong, T. \& Zhang, Q. New amination strategies based on nitrogen-centered radical chemistry. Chem. Soc. Rev. 45, 3069-3087 (2016).

44. Zhang, Q. et al. Metal-free three-component regioselective aminofluorination of styrene derivatives. J. Org. Chem. 82, 8258-8266 (2017).

45. Qiu, S. et al. Palladium-catalyzed intermolecular aminofluorination of styrenes. J. Am. Chem. Soc. 132, 2856-2857 (2010).

46. Jian, W. et al. Iron-catalyzed decarboxylative alkyl etherification of vinylarenes with aliphatic acids as the alkyl source. Angew. Chem. Int. Ed. 56, 3650-3654 (2017).

47. Qian, B. et al. Iron-catalyzed carboamination of olefins: synthesis of amines and disubstituted beta-amino acids. J. Am. Chem. Soc. 139, 13076-13082 (2017).

48. Ye, C. et al. Copper-catalyzed 1,4-alkylarylation of 1,3-enynes with masked alkyl electrophiles. Chem. Sci. 10, 3632-3636 (2019).

49. Zhu, X. et al. Copper-catalyzed radical 1,4-difunctionalization of 1,3-enynes with alkyl diacyl peroxides and $\mathrm{N}$-fluorobenzenesulfonimide. J. Am. Chem. Soc. 141, 548-559 (2019).

50. Sibbald, P. A. \& Michael, F. E. Palladium-catalyzed diamination of unactivated alkenes using $N$-fluorobenzenesulfonimide as source of electrophilic nitrogen. Org. Lett. 11, 1147-1149 (2009).

51. Ingalls, E. L., Sibbald, P. A., Kaminsky, W. \& Michael, F. E. Enantioselective palladium-catalyzed diamination of alkenes using $\mathrm{N}$ fluorobenzenesulfonimide. J. Am. Chem. Soc. 135, 8854-8856 (2013).

52. Xie, J., Wang, Y. W., Qi, L. W. \& Zhang, B. Access to aminated saturated oxygen heterocycles via copper-catalyzed aminooxygenation of alkenes. Org. Lett. 19, 1148-1151 (2017).

53. Xiong, T. et al. Palladium-catalyzed allylic $\mathrm{C}-\mathrm{H}$ amination of alkenes with $N$ fluorodibenzenesulfonimide: water plays an important role. Chem. Commun. 48, 2246-2248 (2012).

54. Zhang, B. \& Studer, A. Copper-catalyzed intermolecular aminoazidation of alkenes. Org. Lett. 16, 1790-1793 (2014)

55. Zhang, G. et al. Highly regioselective radical amination of allenes: direct synthesis of allenamides and tetrasubstituted alkenes. Angew. Chem. Int. Ed. 54, 12649-12653 (2015)

56. Zhang, H. et al. Copper-catalyzed intermolecular aminocyanation and diamination of alkenes. Angew. Chem. Int. Ed. 52, 2529-2533 (2013).

57. Zheng, G. et al. Radical cascade reaction of alkynes with $\mathrm{N}$ fluoroarylsulfonimides and alcohols. Nat. Commun. 6, 7011 (2015).

58. Zheng, G. et al. Highly regio- and stereoselective intermolecular seleno- and thioamination of alkynes. Chem. Eur. J. 22, 3513-3518 (2016). 
59. Knight, L. K. et al. $\beta$-Diketiminato scandium chemistry: synthesis, characterization, and thermal behavior of primary amido alkyl derivatives. Organometallics 23, 2087-2094 (2004).

60. Doucet, H. \& Hierso, J.-C. Palladium-based catalytic systems for the synthesis of conjugated enynes by sonogashira reactions and related alkynylations. Angew. Chem. Int. Ed. 46, 834-871 (2007).

61. Prakash, G. K. S. et al. Synthesis of monofluoroalkenes via Julia-Kocienski reaction. J. Fluor. Chem. 131, 1192-1197 (2010).

62. Zhang, H. et al. Monofluorovinyl tosylate: a useful building block for the synthesis of terminal vinyl monofluorides via Suzuki-Miyaura coupling. Org. Lett. 13, 560-563 (2011).

63. Shao, Q. \& Huang, Y. Direct fluorination of styrenes. Chem. Commun. 51, 6584-6586 (2015).

64. Wu, J., Xiao, J., Dai, W. \& Cao, S. Synthesis of monofluoroalkenes through selective hydrodefluorination of $g e m$-difluoroalkenes with Red-Al ${ }^{\oplus}$. RSC Adv. 5, 34498-34501 (2015)

65. Hamel, J. D., Cloutier, M. \& Paquin, J. F. Ability: an approach to betasubstituted monofluoroalkenes using gem-chlorofluoropropenes. Org. Lett. 18, 1852-1855 (2016).

66. Liu, Q., Shen, X., Ni, C. \& Hu, J. Stereoselective carbonyl olefination with fluorosulfoximines: facile access to $Z$ or $E$ terminal monofluoroalkenes. Angew. Chem. Int. Ed. 56, 619-623 (2017).

67. Chen, X.-W. et al. Hydrogen-transfer-mediated alpha-functionalization of 1,8naphthyridines by a strategy overcoming the over-hydrogenation barrier. Angew. Chem. Int. Ed. 56, 14232-14236 (2017).

68. Kojima, R., Kubota, K. \& Ito, H. Stereodivergent hydrodefluorination of gemdifluoroalkenes: selective synthesis of $(Z)$ - and $(E)$-monofluoroalkenes. Chem. Commun. 53, 10688-10691 (2017).

69. DesMarteau, D. D., Xu, Z. Q. \& Witz, M. N-Fluorobis[(perfluoroalkyl) sulfonyl]imides: reactions with some olefins via.alpha.-fluoro carbocationic intermediates. J. Org. Chem. 57, 629-635 (1992).

70. Zhang, X. et al. Investigation of radical cation in electrophilic fluorination by ESI-MS. Org. Lett. 7, 3877-3880 (2005).

\section{Acknowledgements}

We thank the National Key R\&D Program of China (2017YFA0700103), the NSFC (Grant Nos 21672213, 21871258, and 21922112), the Strategic Priority Research Program of the Chinese Academy of Sciences (Grant No. XDB20000000), and the Haixi Institute of CAS (Grant No. CXZX-2017-P01) for financial support.

\section{Author contributions}

M.T.M. and H.B. conceived the idea. M.T.M., Y.J., and C.Y. conducted the experiments and they contribute equally to this paper. M.-F.C. conducted the DFT calculation. M.I and X.Z. synthesized the substrates and repeated the reactions. M.T.M., Y.J., C.Y., Y.L. and H.B. analyzed the data. Y.L., Z.W., A.S. and H.B. co-wrote the paper. All the authors discussed the results and commented on the manuscript.

\section{Competing interests}

The authors declare no competing interests.

\section{Additional information}

Supplementary information is available for this paper at https://doi.org/10.1038/s41467019-14254-3.

Correspondence and requests for materials should be addressed to H.B.

Peer review information Nature Communications thanks Paul Fleurat-Lessard and the other, anonymous, reviewer(s) for their contribution to the peer review of this work.

Reprints and permission information is available at http://www.nature.com/reprints

Publisher's note Springer Nature remains neutral with regard to jurisdictional claims in published maps and institutional affiliations.

(c) (i) Open Access This article is licensed under a Creative Commons Attribution 4.0 International License, which permits use, sharing, adaptation, distribution and reproduction in any medium or format, as long as you give appropriate credit to the original author(s) and the source, provide a link to the Creative Commons license, and indicate if changes were made. The images or other third party material in this article are included in the article's Creative Commons license, unless indicated otherwise in a credit line to the material. If material is not included in the article's Creative Commons license and your intended use is not permitted by statutory regulation or exceeds the permitted use, you will need to obtain permission directly from the copyright holder. To view a copy of this license, visit http://creativecommons.org/ licenses/by/4.0/.

(c) The Author(s) 2020 